\title{
Association of Coronavirus Disease-19 Infected Mothers with Newborn Infants Health - A Review
}

\author{
Mubashir Zafar* \\ Department of Family and Community Medicine, College of Medicine, University of Hail, Ha'il, Saudi Arabia
}

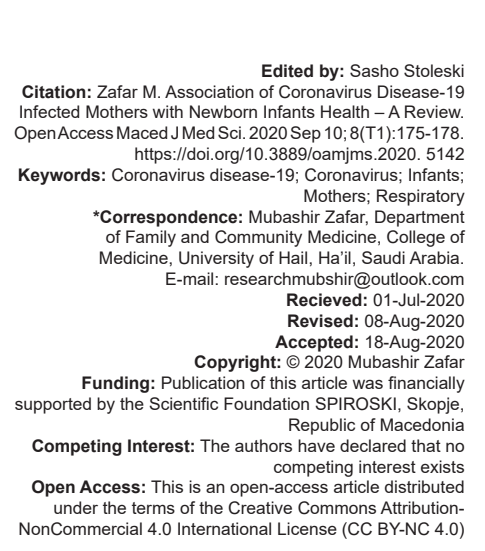

\section{Abstract}

BACKGROUND: Coronavirus (CoV) is an emerging disease and the World Health Organization declared pandemic in February 2020. Infants were born from CoV disease (COVID)-19-positive mothers who were risk of different diseases.

AIM: The aim of this review is to determine the association of infants health with COVID-19-infected mothers.

METHODS: A review of the literature was done for identifying the association of newborn health risk with COVID-19infected mothers. Google Scholar, PubMed, Web of Science, and Scopus were used as search engines.

RESULTS: The common finding among newborn infants from COVID-19-infected mothers were rashes, ulceration on the body, tachypnea, fever, and cough and assisted ventilation was needed to support the ventilation of newborn. Most of the COVID-19-infected women were delivered the preterm baby. The most effective way to reducing the health risk is to screening of mothers and appropriate effective surveillance system should be established.

CONCLUSION: The review has found that infants born with COVID-19-infected mothers had various respiratory disorders. There is a need to coordinated efforts for the management of infants.

\section{Introduction}

In 2019, the first case of new coronavirus (CoV) disease (COVID)-19 was identified at the city Wuhan in China. In February 2020, COVID-19 infection was declared a pandemic by the World Health Organization and almost all countries were affected [1]. The most affected countries are the United States of America, Italy, Spain, Brazil, and France. The most common age groups affected by COVID-19 were the elderly and children [1]. The main reason for elderly population were affected because they have less immune naturally [2]. The other most common vulnerable group were pregnant mothers. The COVID-19-infected mothers were delivered newborn which had different health risk such as rashes and assisted ventilation after birth. The main caused for this health risk was conventional circulation system in mothers and infants which transferred virus from mothers to infants [2].

COVID-19 virus transferred from mothers to infants in many ways [2]. First through respiratory inhalation in which oxygen carries in the blood and then this blood enter the fetal system [2]. Second ingestion, contaminated hand ingest food and through digestion and blood circulation infants were infected [2]. Sepsis is the another way the infant was affected [3].
There are different health risks to the fetus from transmission of COVID-19 from mother. There are different studies showed that newborns were developed sepsis in the $1^{\text {st }}$ day of birth and other researches showed that infants developed pneumonia after in neonatal period [4]. This review helps to find the consistency of results of different studies to either there is the association of COVID-19-infected mothers with the health of infants.

\section{Objective}

The objective of this review is to identify the association of infants health with COVID-19-infected mothers.

\section{Methodology}

A review of the literature was done for identifying various case reports and cases series of COVID-19-infected infants. Google Scholar, Pub Med, Scopus, and Web of Science were used as search engines. Search terms used were "COVID-19," maternal infection, infants, sepsis, and pneumonia. References of the relevant articles were also used for citations. 


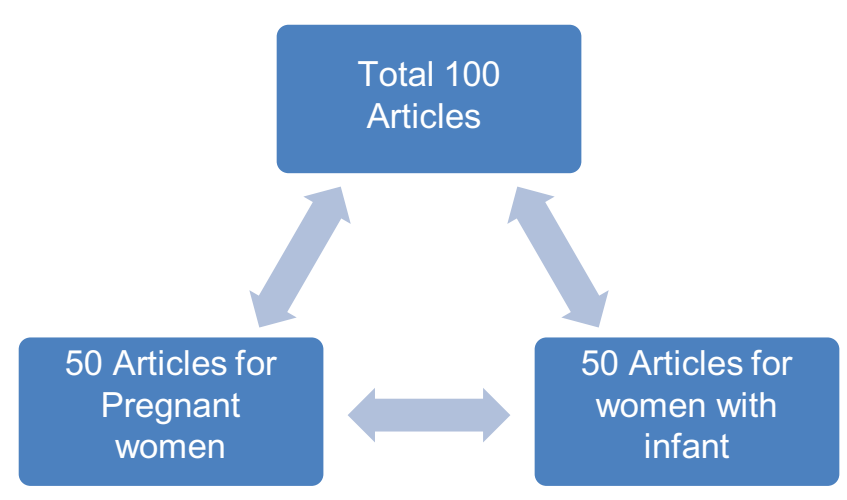

\section{Results and Discussion}

\section{women}

\section{COVID-19 and its effects on pregnant}

This virus belongs to the family of flu virus. The severe acute respiratory syndrome (SARS) virus is also belonging to this family [1]. The previous case series found that case fatality was $25 \%$ from SARS infection in 2003 [5]. Laboratory and the clinical finding of SARS were similar in COVID-19-infected mothers [5]. Chest radiograph and computed tomography scan finding showed that pneumonia in the lung of infected patients [5], [6]. Common complications from the COVID-19-infected women were adult respiratory distress syndrome, lung fibrosis, and pulmonary edema [7]. A study done by scientist found that COVID19 genetically similar to SARS and it comes from bat virus [8].

The virus has $79 \%$ nucleotide identity to SARS-CoV and about $50 \%$ to Middle East respiratory syndrome (MERS)-CoV [8]. Bats appear to be the natural reservoirs of both SARS-CoV and MERSCoV [8]. The emergence of these viruses in humans has been attributed to host switching: The virus "jumped" from an intermediary host species (e.g., civet cats for SARS-CoV and dromedary camels for MERS-CoV) to humans [8]. An intermediary host species is thought to be likely for SARS-CoV-2, although it has been yet to be identified. Sequence data show a high degree (>99.98\%) of similarity of the virus among different patients, suggesting a recent emergence in humans [8].

They have identical pathogenesis to the SARS virus [8]. A recent study found that preterm deliveries were common among COVID-19-infected women [8]. Another study found that cesarean births were common compared to standard vaginal deliveries among infected women [9]. Another study found that fetal movement was reduced and pregnant women had developed dyspnea and anemia after delivery of baby [9].

\section{COVID-19 and its Effects on Infants}

The study was conducted and found that mothers with COVID-19 were delivered preterm and these babies were low birth weight [10]. The result also found that these babies had 1 min Apgar score of 4-6 and 5 min Apgar score of 7-8 [10]. The common practice after delivery, babies were put up on bottle feeding and care of the baby was done in the nursery care center [10]. Another study result found that mother infected with COVID-19 give birth of babies had skin diseases such as itching, rashes, and redness appeared in different parts of the body [11]. Furthermore, babies with macula papules spread on the different region of the body and especially in the forehead with ulceration. The rash on the body of the baby was turned into red papules and it diffuses in nature [11]. Another study found that babies had respiratory distress syndrome which need surfactant and later on developing bronchopulmonary dysplasia [12]. There are various issues during deliveries of babies from COVID-19-infected women. The most common problems were intrauterine growth retardation, miscarriage, and renal failure. After birth, baby needs end tracheal intubation and care in the intensive care unit [13], [14], [15]. Another study found that babies born with COVID-19 mothers had pneumonia [16].

\section{Pregnant Women with COVID-19 Infection}

During the pandemic era of this infectious disease, fundamental changes were occurred in public health and society [17], [18]. The distinctive needs are to developed health promotion plan in which emphasis on awareness regarding COVID-19 infection among pregnant women. Lesson learned from common practice during outbreaks, healthcare providers were reluctant to intervene in the management of pregnant women because they think that any intervention effect the health of fetus [19]. Pregnant women were the most vulnerable group of any society because it needs special care, especially in that situation where the health risk has high due to pandemic. There is a need for specially designed intervention because there is a risk of side effects on the fetus and always in mind for the rule of riskbenefit ratio. The benefit of surveillance systems in that situation should be recognized, maternal and infant outcomes should be monitored and intervention should be promptly initiated to save the life of mother and infant [20]. 
Tour Regulation COVID-19-infected Women

It is recommended that COVID-19-infected women were not travel to the epidemic areas. Various countries have made policies for traveler, especially vulnerable group such as elderly and pregnant women. Consultants obstetric advised should be included in the policy-making. These consultants were give recommendations how to save the health of pregnant women. When pregnant women were travel to the epidemic area, a detailed history of women should be taken and advised the women to report frequently to doctors if any symptoms were appeared. Social distancing and contact tracing should be implemented. Health-care providers, including the consultant's obstetricians, should be stay alert and respond quickly if any worse situation appeared.

\section{COVID-19-infected Pregnant Women Management}

Universal principle for the management of COVID-19 infection was applied to all pregnant women, such measures were quarantine of the suspected person, isolation of confirmed cases, symptomatic management of affairs, testing of suspect cases, contact tracing, oxygen given to severe cases, and antibiotic treatment of secondary infection. Fetus monitoring and assisted ventilation will be given to the women in a severe case of respiratory problem [20]. A specific group of doctors to be alert and monitor the complicated cases of COVID-19-infected pregnant women. Active surveillance should be established to find out the deterioration maternal path of illness [20].

\section{Management of Infants Born from Infected COVID-19 with Mothers}

Coordinated efforts were needed for the management of infants born with COVID-19-infected mother. Appropriate effective surveillance system should be established. Special care unit should be installed at all hospitals, especially primary health-care center.

\section{Conclusion}

The finding of the review concludes that there is vertical transmission of infection from mothers to fetus.
The cases of COVID-19 disease increasing day by day and pregnant mother were affected most, and there is a need to make specific policies to prevent the infection. There is a need for more studies to explore the factors which affect the health of infants from infected mothers of COVID-19. The affective surveillance system should be active. There is a need to include all areas of expertise of doctors and epidemiologist for monitoring the health of mothers and infants. Health system and health-care provider are the vital stakeholder for reducing the infection during pregnancy; it should be improved to prevent the complication associated with COVID-19 disease.

\section{References}

1. Huang $\mathrm{C}$, Wang $\mathrm{Y}$, Li X, Ren L, Zhao J, Hu Y, et al. Clinical features of patients infected with 2019 novel coronavirus in Wuhan, China. Lancet. 2020;395:497-506. https://doi. org/10.1016/s0140-6736(20)30183-5

2. Shek CC, Ng PC, Fung GP, Cheng FW, Chan PK, Peiris MJ, et al. Infants born to mothers with severe acute respiratory syndrome. Pediatrics. 2003;112:e254. https://doi.org/10.1542/ peds.112.4.e254

PMid: 14523207

3. Wong SF, Chow KM, Leung TN, Ng WF, Ng TK, Shek CC, et al Pregnancy and perinatal outcomes of women with severe acute respiratory syndrome. Am J Obstet Gynecol. 2004;191:292-7. https://doi.org/10.1016/j.ajog.2003.11.019 PMid: 15295381

4. Buonsenso D, Costa S, Sanguinetti M, Cattani P, Posteraro B, Marchetti S, et al. Neonatal late onset infection with severe acute respiratory syndrome coronavirus 2 . Am J Perinatol. 2020;37(8):869. https://dx.doi.org/10.1055-0040-1710541

5. Ng PC, Leung CW, Chiu WK, Wong SF, Hon EK. SARS in newborns and children. Biol Neonate. 2004;85:293-8. PMid:15218286

6. Park MH, Kim HR, Choi DH, Sung JH, Kim JH. Emergency cesarean section in an epidemic of the middle east respiratory syndrome: A case report. Korean J Anesthesiol. 2016;69(3):287-91. https://doi.org/10.4097/ kjae.2016.69.3.287

PMid:27274377

7. Robertson CA, Lowther SA, Birch T, Tan C, Sorhage $F$ Stockman L, et al. SARS and pregnancy: A case report. Emerg Infect Dis. 2004;10(2):345-8. https://doi.org/10.3201/ eid1002.030736

PMid: 15030710

8. Lu R, Zhao X, Li J, Niu P, Yang B, Wu H, et al. Genomic characterisation and epidemiology of 2019 novel coronavirus: Implications for virus origins and receptor binding. Lancet. 2020;2:7-9.

9. Yudin $M H$, Steele DM, Sgro MD, Read SE, Kopplin P, Gough KA. Severe acute respiratory syndrome in pregnancy. Obstet Gynecol. 2005;105:124-7. https://doi.org/10.1097/01. aog.0000151598.49129.de

PMid:15625153

10. Chen HJ, Guo JJ, Wang C, Luo F, Yu XC, Zhang W, et al. Clinical characteristics and intrauterine vertical transmission potential of COVID-19 infection in nine pregnant women: A retrospective 
review of medical records. Lancet. 2020;20:30360-3. https://doi. org/10.1016/s0140-6736(20)30360-3

11. Phan T. Novel coronavirus: From discovery to clinical diagnostics. Infect Genet Evol. 2020;79:104211. https://doi. org/10.1016/j.meegid.2020.104211

12. Wong AC, Li X, Lau SK, Woo PC. Global epidemiology of bat coronaviruses. Viruses. 2019;11:E174. https://doi.org/10.3390/ v11020174

PMid:30791586

13. Yu F, Du L, Ojcius DM, Pan C, Jiang S. Measures for diagnosing and treating infections by a novel coronavirus responsible for a pneumonia outbreak originating in Wuhan, China. Microbes Infect. 2020;20:30025-3. https://doi.org/10.1016/j. micinf.2020.01.003

14. Liu $\mathrm{Y}$, Chen H, Tang K, Guo Y. Clinical manifestations and outcome of SARS-CoV-2 infection during pregnancy. J Infect. 2020:2020:28. http://doi.org/10.1016/j.jinf.2020.02.028.

15. Chen N, Zhou M, Dong $X, Q u$ J, Gong F, Han $Y$, et al. Epidemiological and clinical characteristics of 99 cases of 2019 novel coronavirus pneumonia in Wuhan, China: A descriptive study. Lancet. 2020;395:507-13. https://doi.org/10.1016/ s0140-6736(20)30211-7

16. Fang $\mathrm{Y}$, Zhang $\mathrm{H}$, Xie J, Lin $M$, Ying L, Pang $P$, et al. Sensitivity of chest CT for COVID-19: Comparison to RT-PCR. Radiology. 2020;19:E115-7. https://doi.org/10.1148/radiol.2020200432 PMid:32073353

17. Huang C, Wang Y, Li X, Ren L, Zhao J, Hu Y, et al. Clinical features of patients infected with 2019 novel coronavirus in Wuhan, China. Lancet. 2020;2:23-5.

18. Li Q, Guan X, Wu P, Wang X, Zhou L, Tong Y, et al. Early transmission dynamics in Wuhan, China, of novel coronavirusinfected pneumonia. N Engl J Med. 2020;5:4-6.

19. Zhu N, Zhang D, Wang W, Li X, Yang B, Song J, et al. A novel coronavirus from patients with Pneumonia in China, 2019. N Engl J Med. 2020;7:3-5.

20. Stockman LJ, Lowther SA, Coy K, Saw J, Parashar UD. SARS during pregnancy, United States. Emerg Infect Dis. 2004;10:1689-90. https://doi.org/10.3201/eid1009.040244 